\title{
Nebulized Magnesium Sulphate Versus Saline as an Adjuvant in Acute Exacerbation of Chronic Obstructive Pulmonary Disease in a Tertiary Centre of Nepal: A Randomized Control Study
}

Manjita Bajracharya', Ramesh P Acharya ${ }^{2}$, Ram P Neupane ${ }^{2}$, Rekha Sthapit ${ }^{3}$, Apurva R Tamrakar ${ }^{4}$

\author{
Author(s) affiliation \\ 'Department of Family Medicine and \\ Emergency, KIST Medical College, \\ Lalitpur \\ ${ }^{2}$ Department of General Practice and \\ Emergency Medicine, Maharajgunj \\ Medical Campus, Tribhuvan \\ University Teaching Hospital, \\ Institute of Medicine, Kathmandu
}

${ }^{3}$ Department of General Practice and Emergency, National Academy of Sciences, Kathmandu

${ }^{4}$ Kathmandu Eye Center, Lalitpur

\section{Corresponding author}

Manjita Bajracharya, MBBS, MD manji.bajra@gmail.com

\section{Submitted}

Jun 1, 2020

\section{Accepted}

Jan 20, 2021

\begin{abstract}
\section{Introduction}

Magnesium has been shown to have bronchodilator properties in asthma and chronic obstructive pulmonary disease (COPD). Therapeutic benefits of nebulized magnesium in asthma has been seen. The purpose of this study was to compare therapeutic benefits of nebulised magnesium sulphate as an adjuvant with normal saline in patients with COPD exacerbation.
\end{abstract}

\section{Methods}

It was a randomized single blind interventional study of 172 cases of acute exacerbation of COPD presenting (AECOPD) with a peak expiratory flow rate (PEFR) $<300 \mathrm{~L} / \mathrm{min}$ measured 20 min after initial management. Patients received $5 \mathrm{mg}$ salbutamol mixed with $3 \mathrm{ml}$ isotonic magnesium sulphate or $3 \mathrm{ml}$ normal saline on three occasions at 30 min intervals via nebulizer. The primary outcome measured was PEFR at 90 min and hospital admission, noninvasive or invasive ventilation and mortality were taken as secondary outcomes.

\section{Results}

The mean PEFR were $86.3 \pm 11.9 \mathrm{l} / \mathrm{min}, 97.6 \pm 19.1 \mathrm{l} / \mathrm{min}$ and $99.6 \pm 15.2$ $\mathrm{I} / \mathrm{min}$ after nebulization with magnesium sulphate and $79.17 \pm 14.11$ $\mathrm{l} / \mathrm{min}, 90.17 \pm 18.27 \mathrm{l} / \mathrm{min}$ and $93.17 \pm 20.63 \mathrm{l} / \mathrm{min}$ at 30,60 and 90 minutes respectively in normal saline group which were statistically significant differences. Total 91.9\% were admitted in ward and 8.1\% got admitted in Medical and intermediate intensive care units from magnesium group and $81.7 \%$ were admitted in ward and $18.3 \%$ required ICU admissions in saline group. Differences in ventilation and mortality were insignificant.

\section{Conclusion}

Nebulized magnesium sulphate as an adjuvant to salbutamol treatment in the setting of AECOPD has therapeutic benefit on PEFR but no effect in terms of hospital admission, requirement of invasive or non-invasive ventilation and mortality.

\section{Keywords}

Chronic obstructive pulmonary disease, magnesium sulphate, peak expiratory flow rate 


\section{INTRODUCTION}

$\mathrm{C}$ hronic obstructive pulmonary disease (COPD) is a disease characterized by airflow limitation due to infiltration of small airways with inflammatory cells causing narrowing and destruction of the elastic recoil of lung parenchyma resulting in hyperinflation. ${ }^{1}$ Acute exacerbation of chronic obstructive pulmonary disease (AECOPD) is one of the commonest encountered disease condition by any doctor at an Emergency Room. ${ }^{2}$ Globally an estimated $10-20 \%$ of the population are COPD patients resulting in more than 3 million deaths per year. ${ }^{3}$ More than $90 \%$ of COPD deaths occur in low and middle-income countries. In context of Nepal, it has been estimated that COPD accounts for more than $43 \%$ of the non-communicable disease burden and $2.56 \%$ of hospitalization. ${ }^{3}$

The management of AECOPD is mainly focused at arresting the pathogenesis and reversing potential precipitating factors, especially infection with use of antibiotics, steroids, anti-cholinergics and beta-2 agonist. 4,5 Antibiotics and steroids have played a significant role in controlling infection and inflammation thereby facilitating airway and preventing exacerbation. ${ }^{6}$ Beta- 2 agonist along with anti-cholinergic facilitate bronchodilation and thus relieve dyspnea and improve respiratory parameters. ${ }^{4,7}$ Magnesium sulphate is thought to act by inhibiting smooth muscle contraction by facilitating calcium uptake into the sarcoplasmic reticulum. It inhibits the slow inward calcium current and calcium induced calcium release. ${ }^{8}$ It has also been suggested to inhibit histamine release from mast cells and Acetylcholine release from cholinergic nerve terminal to act via central sedative action. ${ }^{9}$ Magnesium sulphate has proven to be beneficial in acute severe asthma when administered via intravenous and nebulized route. ${ }^{1}$ Though not proven, citing the similarity in pathophysiology of acute severe asthma and AECOPD (e.g.: bronchial hyper-responsiveness), the use of nebulized magnesium sulphate is as attractive as a therapeutic option because it is can be easily administered, economically sound and with minimal side effects. ${ }^{10}$ The aim of this study was to compare the efficacy of salbutamol and magnesium sulphate nebulization verus salbutamol and normal saline nebulization in terms of PEFR in acute exacerbation of COPD patients. The secondary objective was to compare outcomes in both groups in terms of hospital admission, requirement of invasive or non-invasive ventilation and mortality.

\section{METHODS}

This was a single blinded randomized control trial conducted in 172 patients of Emergency Room of Tribhuvan University Teaching Hospital from
December 2016 to March 2017. On presentation to the Emergency Department with a provisional diagnosis of an AECOPD, potential subjects were clinically assessed and received standard initial treatment (i.e. $5 \mathrm{mg}$ salbutamol and $250 \mathrm{mcg}$ ipratropium bromide by nebulization and $200 \mathrm{mg}$ hydrocortisone), oxygen (2 l/min nasal prongs) was given if oxygen saturations on room air were $<90 \%$. Only subjects more than 40 years ${ }^{11,12}$ with a peak expiratory flow rate (PEFR) $<300 \mathrm{l} / \mathrm{min}$, measured 20 min after commencement of the initial salbutamol/ipratropium nebulization were enrolled in the trial. Referred case from other hospitals with prior management, patients who received premedication with bronchodilator 6 hours prior and steroid 12 hours prior to trial and contraindications to magnesium sulphate (hypersensitivity, diabetic coma, heart block, myocardial damage, hypomagnesaemia, hypercalcemia), patients unable to perform spirometry and with systolic blood pressure less than $100 \mathrm{mmHg}$, evidence of pneumothorax, chronic kidney disease patients and pregnant women and those with motor neuron diseases were excluded from the study.

During this 20 min period informed consent was obtained and a brief questionnaire administered, obtaining information with regard to duration and severity of symptoms, medication use and smoking status. Routine blood tests creatinine, sodium, potassium, full blood count, ABG were done. The patients were randomized by drawing lots to receive one of two sequences of treatment. The medications was prepared by the investigator and were labeled as A (combination of magnesium sulphate and salbutamol) or B (salbutamol and normal saline). Thus the patients were blinded to the nature of the treatment given to a patient. Any side effects noted by the patient or physicians were recorded

The patients received by nebulization $5 \mathrm{mg}$ salbutamol mixed with A) $3 \mathrm{ml}$ isotonic magnesium sulphate : $50 \%$ solution, $8.30 \mathrm{mosm} / \mathrm{ml}, 500 \mathrm{mg} /$ $\mathrm{ml}$ made isotonic by dilution in sterile water at ratio 1:14 (1 ml magnesium sulphate and $14 \mathrm{ml}$ sterile water for injection) Or B) $3 \mathrm{ml}$ normal saline on three occasions at 30 min intervals. PEFR using a handheld spirometer on first referral ('presentation'), before the first study ('baseline' PEFR), before each subsequently and then 30 min after the last nebulization. Three measurements were made at each time point and the highest recording used for analysis. Vital monitoring was done as part of routine clinical observations and otherwise as clinically indicated. After the final recordings the decision to admit the patients was made at the discretion of the clinical team. The patient was followed up for one week after admission in ward and ICU, outcome was noted in terms of requirement of ventilatory support and mortality. 
IBM SPSS software version 20 was used to enter data and analyze the data. Mean and standard deviation were calculated for each quantitative variable. Z-test for was used for mean difference for PEFR and vital signs comparison and chi square test for the other variables to establish the level of significance between the variables. P-value of $<0.05$ was considered to be statistically significant. Study was conducted after getting approval from Institutional Review Comimtee (IRC) of Institute of Medicine. Written consent was taken from the partifipants for their enrollment in the study.

\section{RESULTS}

Total numbers of 200 patients were assessed for the study, among them 172 were included and 28 patients excluded. Recruited 172 patients were randomized, nebulized with the corresponding drugs and evaluated for the response and followed till discharge or mortality if any.

According to inclusion criteria, patients $>40$ years were only included in the study. Out of which mean age was $70.01 \pm 10.39$ years in magnesium and $68.58 \pm 14.71$ years in normal saline group. A total of
Table 1. Sex distribution $(n=172)$

\begin{tabular}{ccccc}
\hline Sex & $\begin{array}{c}\text { Magnesium } \\
\text { sulphate group }\end{array}$ & $\begin{array}{c}\text { Normal saline } \\
\text { group }\end{array}$ & Total & $\begin{array}{c}\text { p- } \\
\text { value }\end{array}$ \\
\hline Male & $43(50.0 \%)$ & $37(43.02 \%)$ & 80 & 0.11 \\
Female & $43(50.0 \%)$ & $49(56.98 \%)$ & 92 & \\
Total & $86(100.0 \%)$ & $86(100.0 \%)$ & 172 & \\
\hline
\end{tabular}

$17(9.9 \%)$ were $41-50$ years of age, $27(15.7 \%)$ in 51 60 years age group, $55(32.0 \%)$ in $61-70$ years age group, 39(22.7\%) in 71-80 years group, 26(15.1\%) in $81-90$ years group and total 8 (4.6\%)patients more than 90 years of age. Most common prevalence was seen in age group 61-70 years.

The mean PEFR at 0 min was $60 \mathrm{l} / \mathrm{min}$ in both groups. The mean PEFR was $86.3 \pm 119 \mathrm{l} / \mathrm{min}$ at 30 minutes, $97.6 \pm 19.1 \mathrm{l} / \mathrm{min}$ at $60 \mathrm{~min}$ and $99.6 \pm 15.2 \mathrm{l} / \mathrm{min}$ at $90 \mathrm{~min}$ after nebulization with salbutamol and magnesium sulphate.The mean PEFR were $79.17 \pm 14.11 \mathrm{l} / \mathrm{min}, 90.17 \pm 18.27 \mathrm{l} / \mathrm{min}$ and $93.17 \pm 20.63 \mathrm{l} / \mathrm{min}$ at 30,60 and 90 minutes respectively in salbutamol and saline group which were statistically significant. Heart rate and

\section{Enrollment \\ $\downarrow$ \\ Assessed for eligibility \\ $(n=200)$}

Group $A$ = combination of magnesium sulphate and salbutamol $(n=86)$

Allocated to intervention $(n=86)$

Received allocated intervention $(n=86)$

Did not receive allocated intervention $(n=0)$

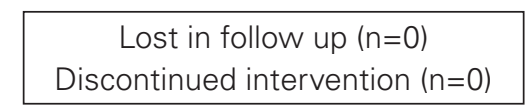

Analysed $(n=86)$

Excluded from analysis $(n=0)$
Excluded $(n=28)$

- Not meeting inclusion criteria $(n=6)$

- Declined to participate $(n=5)$

- Unable to perform adequate spirometry $(n=3)$

- Referral to other center due to unavailability of bed $(n=7)$

- Left against medical advice $(n=2)$

- Premedication from other centers $(n=5)$

Randomized Group $B=$ combination of normal saline $(n=172) \quad$ and salbutamol $(n=86)$

$\downarrow$

Allocation

Allocated to intervention $(n=86)$

Received allocated intervention $(n=86)$

Did not receive allocated intervention $(n=0)$

$\downarrow$

Follow-up

Lost in follow up $(n=0)$

Discontinued intervention $(n=0)$

$\downarrow$

Analysis

Analysed $(n=86)$

Excluded from analysis $(n=0)$

Fig 1. CONSORT flow diagram 
Table 2. PEFR change at baseline and $90 \mathrm{~min}$ in response to nebulization $(n=172)$

\begin{tabular}{cccc}
\hline $\begin{array}{c}\text { PEFR (in } \\
\text { L/min) at }\end{array}$ & $\begin{array}{c}\text { Magnesium } \\
\text { sulphate group }\end{array}$ & $\begin{array}{c}\text { Normal } \\
\text { saline group }\end{array}$ & p-value \\
\hline 0 min & 60 & 60 & \\
30 min & $86.3 \pm 11.9$ & $79.17 \pm 14.11$ & 0.009 \\
60 min & $97.6 \pm 19.1$ & $90.17 \pm 18.27$ & 0.22 \\
90 min & $99.6 \pm 15.2$ & $93.06 \pm 20.63$ & 0.08 \\
\hline
\end{tabular}

Table 3. Disposition of patients $(n=172)$

\begin{tabular}{lcccc}
\hline $\begin{array}{c}\text { Admission } \\
\text { area }\end{array}$ & $\begin{array}{c}\text { Magnesium } \\
\text { sulphate } \\
\text { group }\end{array}$ & $\begin{array}{c}\text { Normal } \\
\text { saline } \\
\text { group }\end{array}$ & Total & $\begin{array}{c}\text { p- } \\
\text { value }\end{array}$ \\
\hline Ward & $79(92 \%)$ & $70(81 \%)$ & 149 & 0.11 \\
ICU & $7(8 \%)$ & $16(19 \%)$ & 23 & 0.12 \\
\hline
\end{tabular}

Table 4. Requirement of ventilator support (NIV/IV) in relation to treatment $(n=172)$

\begin{tabular}{cccc}
\hline $\begin{array}{c}\text { NIV/IV } \\
\text { support }\end{array}$ & $\begin{array}{c}\text { Magnesium } \\
\text { sulphate group }\end{array}$ & $\begin{array}{c}\text { Normal } \\
\text { saline group }\end{array}$ & p-value \\
\hline Yes & 0 & $1(1.7 \%)$ & 0.08 \\
No & $86(100 \%)$ & $85(98.3 \%)$ & \\
\hline
\end{tabular}

Table 5. Treatment relation with mortality $(n=172)$

\begin{tabular}{cccc}
\hline Mortality & $\begin{array}{c}\text { Magnesium } \\
\text { sulphate group }\end{array}$ & $\begin{array}{c}\text { Normal } \\
\text { saline group }\end{array}$ & p-value \\
\hline Yes & 0 & $1(1.7 \%)$ & 0.08 \\
No & $86(100 \%)$ & $85(98.3 \%)$ & \\
\hline
\end{tabular}

blood pressure change in between two groups was statistically insignificant. Z-test was used to calculate mean difference.

A total of $8 \%$ of patients got admitted in intensive care units and $92 \%$ got admitted in ward in magnesium group. In saline group, 19\% got admitted in intensive care while $81 \%$ got admitted in ward. In saline group, $1.7 \%$ of the patients underwent ventilatory support which was statistically insignificant. Chi-square test was used to compare differences between these variables. In terms of mortality, $1.7 \%$ of patients expired in normal saline group which was also statistically insignificant.

\section{DISCUSSION}

The present study was conducted to investigate the role of nebulized magnesium sulphate combined with salbutamol versus salbutamol alone in patients with acute exacerbation of COPD. Our study showed that nebulization of combination of magnesium sulphate and salbutamol had beneficial effect in bronchodilation compared with plain salbutamol nebulization in patients with acute exacerbation of COPD. However, there were no significant differences between the two groups with regard to side effects and rates of hospitalization, ventilator support or mortality.

Several methodological issues were considered in the design of the study that is relevant to its interpretation. The primary reason for including only subjects with an PEFR $<300 \mathrm{l} / \mathrm{min}$ predicted (measured 20 min after commencement of initial salbutamol and ipratropium) was that, in groups with asthma, an effect with intravenous magnesium has been found in those with more severe disease. ${ }^{13} \mathrm{~A}$ good correlation between forced expiratory volume in 1 second $\left(F E V_{1}\right)$ and PEFR has been reported in COPD, further validating the possible use of home PEFR as a surrogate for office-based or laboratory spirometric monitoring. ${ }^{15}$

The reason for the initial bronchodilator administration of salbutamol/ipratropium nebulizers at presentation was safety as well as ensuring some standardization of bronchodilator treatment in the $20 \mathrm{~min}$ prior to randomization. Bronchodilators are considered first-line treatment as per guidelines for managing AECOPD but may not recommend a specific dose. ${ }^{16}$ In stable COPD it has been shown that $88 \%$ of patients achieved $90 \%$ of maximal bronchodilator with doses of inhaled salbutamol $\leq 1.2 \mathrm{mg} .{ }^{17}$ However, this predosing with bronchodilators could have already led to their maximum bronchodilator response before administration of magnesium.

The magnesium used was formulated as an isotonic solution. This was important because both hypotonic and hypertonic nebulizer solutions can induce bronchoconstriction in patients with bronchial hyper-responsiveness. ${ }^{18}$ Skorodin et al reported a significant increase in peak expiratory flow from initiation to 30 and 45 min later and a statistically non-significant trend towards a reduced need for hospitalization with intravenous magnesium which support results of our study. ${ }^{19}$ This study by Gonzalez et al and Amaral et al with intravenous magnesium vs placebo also supports the bronchodilator effects of magnesium as an adjunct rather than sole bronchodilator and an increase in respiratory muscle strength measured as maximum inspiratory pressure. ${ }^{20}$ Together these studies indicate that a single intravenous dose of magnesium has clinical efficacy in both stable and acute exacerbations of COPD.

More recent study on multiple nebulization of terbutaline plus ipratropium or terbutaline plus a once-only bolus of intravenous magnesium followed by repeated nebulized terbutaline and nebulized 
magnesium showed no significant difference between the two groups in their primary outcome variable (which included hospital admission, intubation and hospital death rates) similar to our study result. ${ }^{21}$ In a similar study by, Edwards et al. the primary outcome variable of $\mathrm{FEV}_{1}$ measured at 90 min showed no statistically significant difference between the placebo group and the magnesium sulphate group after adjustment for baseline $F E V_{1}$. Differences in the need for hospital admission did not show significance either which was similar to our study. ${ }^{22}$

The relevance of our study to the studies done in asthma is equally comparable because the reported efficacy of magnesium in asthma exacerbations is the pretext for its use in COPD. In asthma, magnesium has been administered both intravenously and via the nebulized route. The recent Cochrane review and meta-analysis of intravenous magnesium reported an improvement only in the severe subgroup in whom peak expiratory flow and $\mathrm{FEV}_{1}$ has shown to improve ${ }^{23}$ However, the Cochrane review of nebulized magnesium as an adjunct in acute asthma reported a non-significant improvement in pulmonary function in the nebulized magnesium group, but significant heterogeneity between trials precluded a definitive conclusion.

Furthermore, the benefits of repeated administration of nebulized magnesium include ease of administration with no need for an intravenous line. With regard to the dose of magnesium, this was based on the work in asthma. ${ }^{24}$ Most of our patients did show a significant response to nebulized therapy. We did not continue nebulization of magnesium sulphate beyond three doses although further doses of salbutamol are recommended if a patient shows only partial response to initial dose. Therefore, a possible difference between the two groups could have been masked by the small sample size. Longer follow up period for the patients would have been better for seeking any long term benefits or side effects. Since this was a single centre based study, further multicentred studies are recommended before generalization of the study is done.

\section{CONCLUSION}

This randomized single blinded study indicated that the administration of nebulized magnesium sulphate along with salbutamol in patients with COPD exacerbation demonstrate therapeutic benefit in bronchodilation in terms of improvement in PEFR however there was no evidence of significant alteration in the vital signs, hospital admission, or any form of ventilation and mortality.

\section{CONFLICT OF INTEREST}

None declared.

\section{REFERENCES}

1. Aggarwal $P$, Sharad $S$, Handa $R$, et al. Comparison of nebulised magnesium sulphate and salbutamol combined with salbutamol alone in the treatment of acute bronchial asthma: a randomised study. Emerg Med J 2006; 23: 358-62.

2. Welniak TJ, Panzenbeck A, Koyfman A, et al. Chronic obstructive pulmonary disease: Emergency care in acute exacerbation. African J Emerg Med 2015; 5: 75-84.

3. Longmore M, Wilkinson I, Baldwin A, et al. Oxford Handbook of Clinical Medicine-Mini Edition. OUP Oxford, 2014.

4. Stoodley RG, Aaron SD, Dales RE. The role of ipratropium bromide in the emergency management of acute asthma exacerbation: a metaanalysis of randomized clinical trials. Ann Emerg Med 1999; 34: 8-18.

5. Plotnick $L H$, Ducharme FM. Should inhaled anticholinergics be added to $\beta_{2}$ agonists for treating acute childhood and adolescent asthma? A systematic review. Bmj 1998; 317: 971-977.

6. Herath SC, Poole P. Prophylactic antibiotic therapy for chronic obstructive pulmonary disease (COPD). Cochrane Libr.

7. Melani AS. Long-acting muscarinic antagonists. Expert Rev Clin Pharmacol 2015; 8: 479-501.

8. Mathew R, Altura BM. Magnesium and the lungs. Magnesium 1988; 7: 173-187.

9. Mangat HS, D'souza GA, Jacob MS. Nebulized magnesium sulphate versus nebulized salbutamol in acute bronchial asthma: a clinical trial. Eur Respir J 1998; 12: 341-344.

10. Papiris SA, Manali ED, Kolilekas L, et al. Acute severe asthma. Drugs 2009; 69: 2363-2391.

11. Bhandari R, Sharma R. Epidemiology of chronic obstructive pulmonary disease: a descriptive study in the mid-western region of Nepal. Int J Chron Obstruct Pulmon Dis 2012; 7: 253.

12. Adhikari TB, Neupane D, Kallestrup P. Burden of COPD in Nepal. Int J Chron Obstruct Pulmon Dis 2018; 13: 583

13. Shrestha B, Dhungel S, Chokhani R. Echocardiography based cardiac evaluation in the patients suffering from chronic obstructive pulmonary disease. Nepal Med Coll J 2009; 11: 14-18.

14. Jain $P$, Kavuru MS, Emerman $C L$, et al. Utility of peak expiratory flow monitoring. Chest 1998; 114: 861-876

15. Kelly CA, Gibson GJ. Relation between FEV1 and peak expiratory flow in patients with chronic airflow obstruction. Thorax 1988; 43: 335

16. Pearson M. Chronic obstructive pulmonary disease: national clinical guideline on management of chronic obstructive pulmonary disease in adults in primary and secondary care. Thorax 2004; 59: $1-232$.

17. Teale C, Morrison JF, Page RL, et al. Dose response to inhaled salbutamol in chronic obstructive airways disease. Postgrad Med J 1991; 67: 754-756.

18. Beasley R, Rafferty $P$, Holgate $S T$. Adverse reactions to the non-drug constituents of nebuliser solutions. Br J Clin Pharmacol 1988; 25: 283-287.

19. González JA, García CH, González PA, et al. Effect of intravenous magnesium sulfate on chronic obstructive pulmonary disease exacerbations requiring hospitalization: A randomized placebocontrolled trial. Arch Bronconeumol ((English Ed 2006; 42: 384387.

20. Amaral AF, Gallo L, Vannucchi $H$, et al. The effect of acute magnesium loading on the maximal exercise performance of stable chronic obstructive pulmonary disease patients. Clinics 2012; 67: 615-622.

21. Nouira S, Bouida W, Grissa MH, et al. Magnesium sulfate versus ipratropium bromide in chronic obstructive pulmonary disease exacerbation: a randomized trial. American journal of therapeutics, 2014, pp. 152-158. 
22. Edwards L, Shirtcliffe P, Wadsworth $K$, et al. Use of nebulised magnesium sulphate as an adjuvant in the treatment of acute exacerbations of COPD in adults: a randomised double-blind placebo-controlled trial. Thorax 2013; 68: 338-343.

23. Rowe BH, Bretzlaff J, Bourdon C, et al. Magnesium sulfate for treating exacerbations of acute asthma in the emergency department. Cochrane Libr.

24. Hughes R, Goldkorn A, Masoli M, et al. Use of isotonic nebulised magnesium sulphate as an adjuvant to salbutamol in treatment of severe asthma in adults: randomised placebo-controlled trial. Lancet 2003; 361: 2114-2117. 